\title{
Analysis and optimization of a composite leaf spring
}

\author{
Mahmood M. Shokrieh *, Davood Rezaei \\ Composites Research Laboratory, Department of Mechanical Engineering, Iran University of Science and Technology, \\ Narmak, Tehran 16844, Iran
}

\begin{abstract}
A four-leaf steel spring used in the rear suspension system of light vehicles is analyzed using ANSYS V5.4 software. The finite element results showing stresses and deflections verified the existing analytical and experimental solutions. Using the results of the steel leaf spring, a composite one made from fiberglass with epoxy resin is designed and optimized using ANSYS. Main consideration is given to the optimization of the spring geometry. The objective was to obtain a spring with minimum weight that is capable of carrying given static external forces without failure. The design constraints were stresses (Tsai-Wu failure criterion) and displacements. The results showed that an optimum spring width decreases hyperbolically and the thickness increases linearly from the spring eyes towards the axle seat. Compared to the steel spring, the optimized composite spring has stresses that are much lower, the natural frequency is higher and the spring weight without eye units is nearly $80 \%$ lower.
\end{abstract}

(C) 2003 Elsevier Science Ltd. All rights reserved.

Keywords: Leaf spring; Composite; Shape optimization; Finite element; Composite joints; Natural frequency; Suspension system; Composite beam

\section{Introduction}

Composite materials are now used extensively in the automotive industry to take the place of metal parts. Several papers were devoted to the application of composite materials for automobiles. Some of these papers are reviewed here, with emphasis on those papers that involve composite leaf springs. Breadmore $[1,2]$ studied the application of composite structures for automobiles. Moris [3] concentrated on using composites in the rear suspension system. Daugherty [4] studied the application of composite leaf spring in heavy trucks. $\mathrm{Yu}$ and Kim [5] designed and optimized a double tapered beam for automotive suspension leaf spring. Corvi [6] investigated a preliminary approach to composite beam design and used it for a composite leaf spring.

Springs are crucial suspension elements on cars, necessary to minimize the vertical vibrations, impacts and bumps due to road irregularities and create a comfortable ride. A leaf spring, especially the longitudinal type, is a reliable and persistent element in automotive suspension systems. These springs are usually formed by stacking leafs of steel, in progressively longer lengths on top of each other, so that the spring is thick

\footnotetext{
${ }^{*}$ Corresponding author. Fax: +98-21-200-0016.

E-mail address: shokrieh@iust.ac.ir (M.M. Shokrieh).
}

in the middle to resist bending and thin at the ends where it attaches to the body. A leaf spring should support various kinds of external forces shown in Fig. 1, but the most important task is to resist the variable vertical forces.

Vertical vibrations and impacts are buffered by variations in the spring deflection so that the potential energy is stored in spring as strain energy and then released slowly. So, increasing the energy storage capability of a leaf spring ensures a more compliant suspension system. The amount of elastic energy that can be stored by a leaf spring volume unit [6] is given by Eq. (1).

$S=\frac{1}{2} \frac{\sigma^{2}}{E}$

where $\sigma$ is the maximum allowable stress induced into the spring and $E$ is the modulus of elasticity, both in the longitudinal direction. Considering that the dominant loading on leaf spring is vertical force [7], the Eq. (1) shows that a material with maximum strength and minimum modulus of elasticity in the longitudinal direction is the most suitable material for a leaf spring. Fortunately, composites have these characteristics [8]. One of the most advantageous reasons for considering composites instead of steel is their weight. Another important characteristics of composites which make them excellent for leaf spring are: higher strength-to-weight 


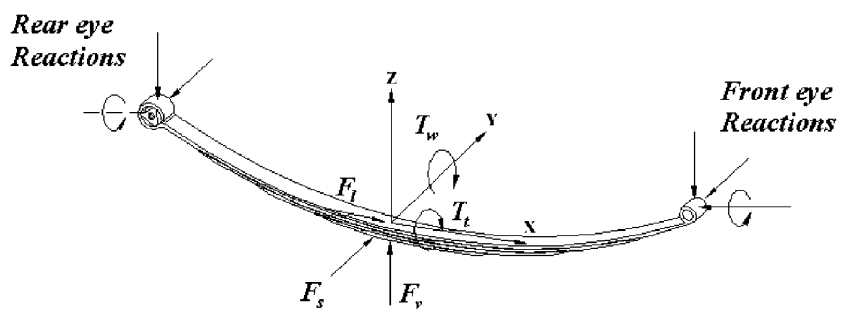

Fig. 1. Forces acting at the axle seat of a leaf spring. $F_{\mathrm{V}}$ : vertical load, $F_{\mathrm{s}}$ : side load, $F_{\mathrm{t}}$ : longitudinal load, $T_{\mathrm{t}}$ : twisting torque, $T_{\mathrm{w}}$ : windup torque.

ratio (up to five times that of steel), no interleaf friction, superior fatigue strength, "fail-safe" capabilities, excellent corrosion resistance, smoother ride, higher natural frequency, etc.

In the present work, a four-leaf steel spring used in passenger cars is replaced with a composite spring made of glass/epoxy composites. The main objective was the shape optimization of the spring to give the minimum weight.

\section{Steel leaf spring}

Parameters of the four-leaf steel spring used in this work are shown in Table 1. This spring is unsymmetrical so that the length of the front half is $559 \mathrm{~mm}$ and the rear half is $686 \mathrm{~mm}$. Every leaf is $50 \mathrm{~mm}$ wide and $7 \mathrm{~mm}$ thick.

Experimental results from testing the steel leaf spring under static and full bump loading containing the stresses and deflections are listed in the Table 2.

Table 1

Parameters of steel leaf spring

\begin{tabular}{ll}
\hline Parameter & Value \\
\hline Total length & $1245 \mathrm{~mm}$ \\
Front half (the arc length between & $559 \mathrm{~mm}$ \\
the axle seat and the front eye) & \\
Arc height at axle seat & $120.4 \mathrm{~mm}$ \\
Spring rate & $20.76 \mathrm{~N} / \mathrm{mm}$ \\
Normal static loading & $2500 \mathrm{~N}$ \\
Full bump loading & $4660 \mathrm{~N}$ \\
Available space for spring width & $50-60 \mathrm{~mm}$ \\
Spring weight & $9.2 \mathrm{~kg}$ \\
\hline
\end{tabular}

Table 2

Results of experiments on the steel leaf spring

\begin{tabular}{lll}
\hline Static loading & Load $(\mathrm{N})$ & $2500 \pm 115$ \\
& Deflection $(\mathrm{mm})$ & 120.4 \\
& Stress $(\mathrm{MPa})$ & $483.3 \pm 22.2$ \\
& Load $(\mathrm{N})$ & $4660 \pm 460$ \\
Full bump & Deflection $(\mathrm{mm})$ & 209.3 \\
& Stress $(\mathrm{MPa})$ & $844.4 \pm 83.3$ \\
\hline
\end{tabular}

Information in Table 2 is not sufficient to design a composite leaf spring. So, a stress analysis was performed using finite element method. All the calculations were done using the version 5.4 of ANSYS [9]. In the finite element modeling, every leaf was modeled with eight-node 3D brick elements (SOLID 45) and then fivenode 3D contact elements (CONTACT 49) were used to represent contact and sliding between adjacent surfaces of leaves. An average coefficient of friction 0.03 was taken between surfaces [7]. The axle seat of spring was assumed to be fixed and loading was applied at the eyes corresponding to the length of each half of spring.

A finite element stress analysis was performed under static and full bump loading. Another analytical solution was carried out using the SAE standard design formulas for leaf springs [7]. The results of experimental, analytical and finite element methods are shown and compared in Table 3.

Maximum normal stress $\sigma_{x x}$ from finite element analysis was compared to the experimental solution under static and full bump loading and has $23 \%$ and $3 \%$ error, respectively. There is a good correlation for maximum deflection from all three methods. The maximum deflection given in Table 3 is related to the rear half deflection. The front half of spring has a deflection about $78 \mathrm{~mm}$.

\section{Composite leaf spring}

Considering several types of vehicles that have leaf springs and different loading on them, various kinds of composite leaf spring have been developed. In some designs the thickness and width of the spring are fixed along the longitudinal axis [10]. In some types, the width is kept fixed and thickness is variable along the spring [11]. In other types width is fixed and in each section the thickness is varying hyperbolically so that at two edges the thickness is minimum and in the middle is maximum [12]. Another design is presented by $\mathrm{Yu}$ and $\mathrm{Kim}$ [5] so that the width and thickness are fixed from eyes to the middle of spring and towards the axle seat the width decreases hyperbolically and thickness increases linearly. In their design the curvature of spring and fiber misalignment in the width and thickness direction are neglected. Therefore, in this study the simplified assumptions are removed and the spring is designed using a more realistic situation.

\subsection{Material selection}

The material used directly affects the quantity of storable energy in the leaf spring. The specific strain energy can be written as Eq. (2). 
Table 3

Stress analysis of leaf spring using experimental, analytical and finite element methods

\begin{tabular}{|c|c|c|c|c|c|c|}
\hline \multirow{2}{*}{ Loading $(\mathrm{kg})$} & \multicolumn{2}{|c|}{ Analytical solution } & \multicolumn{2}{|c|}{ Experimental method } & \multicolumn{2}{|c|}{ Finite element method } \\
\hline & $\delta(\mathrm{mm})$ & $\sigma(\mathrm{MPa})$ & $\delta(\mathrm{mm})$ & $\sigma(\mathrm{MPa})$ & $\delta(\mathrm{mm})$ & $\sigma(\mathrm{MPa})$ \\
\hline $250 \pm 11.5$ & 120.4 & 471.22 & 120.4 & $483.3 \pm 22.2$ & 127.8 & 578.6 \\
\hline $466 \pm 46$ & 209.3 & 878.90 & 209.3 & $844.4 \pm 83.3$ & 209.7 & 905 \\
\hline
\end{tabular}

$S=\frac{1}{2} \frac{\sigma_{\mathrm{t}}^{2}}{\rho E}$

where $\sigma_{\mathrm{t}}$ is the allowable stress, $E$ is the modulus of elasticity and $\rho$ is the density. The specific strain energy of steel spring and some composites are compared in Fig. 2, when the ultimate static strength is used for $\sigma_{\mathrm{t}}$. The S2-Glass/epoxy value is set to 1 and other values are expressed as their relative percentages to it. Regarding the dynamic nature of loading on spring, the hatched regions identify the quantity of specific strain energy in dynamic loading when the fatigue strength is used for $\sigma_{\mathrm{t}}$.

Considering the Fig. 2, in dynamic loading the HTcarbon/epoxy is capable of storing the greatest amount of energy. This material also has high strength and stiffness and low weight. But on the other hand, it has low impact strength and in the case of contact with a metal, galvanic the corrosion would cause some problems. The very high cost of this material is another drawback for practical use.

Compared to carbon fibers, glass fibers have lower strength and stiffness, higher density, better corrosion resistance, higher impact strength and lower cost. A good combination between the material properties and the cost is obtained with the glass fibers.

Glass fibers consist of two major types E and S2. Although S2 fibers have better mechanical properties

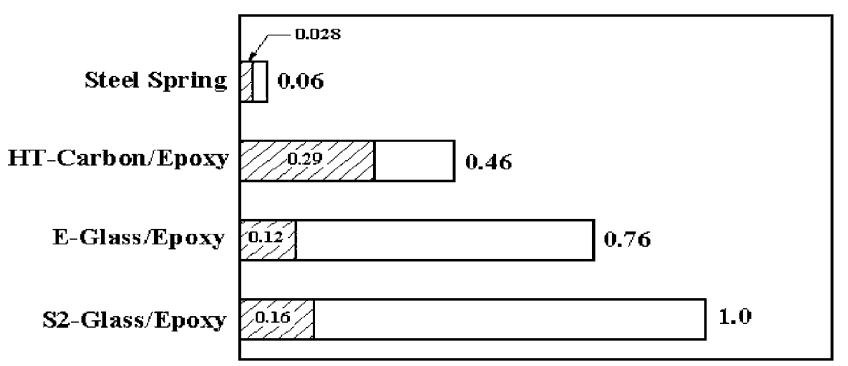

Fig. 2. The specific strain energies of the spring materials [5].

Table 4

Mechanical properties of the E-glass/epoxy

\begin{tabular}{llll}
\hline (E-glass/epoxy) & & & \\
\hline$E_{x x}(\mathrm{GPa})$ & 27.7 & $X_{\mathrm{T}}(\mathrm{MPa})$ & 589.8 \\
$E_{y y}(\mathrm{GPa})$ & 8.4 & $X_{\mathrm{C}}(\mathrm{MPa})$ & 450 \\
$G_{x y}(\mathrm{GPa})$ & 2.3 & $Y_{\mathrm{T}}(\mathrm{MPa})$ & 48.68 \\
$v_{x y}$ & 0.237 & $Y_{\mathrm{C}}(\mathrm{MPa})$ & 120.7 \\
$\rho\left(\mathrm{kg} / \mathrm{m}^{3}\right)$ & 1608 & $S_{x y}(\mathrm{MPa})$ & 43.54 \\
\hline
\end{tabular}

than E fibers, but the cost of E fibers is much lower than S2 fibers. So in the present work the E-glass/epoxy is selected as the spring material. Mechanical properties of this material are listed in Table 4. This material was assumed to be linearly elastic and orthotropic.

\subsection{Lay up selection}

According to the Eq. (1), the stored energy in a leaf spring varies directly with the square of maximum allowable stress and inversely with the modulus of elasticity both in the longitudinal direction. Composite materials like the E-glass/epoxy in the direction of fibers have good characteristics for storing strain energy. So, the lay up is selected to be unidirectional along the longitudinal direction of the spring. The unidirectional lay up may weaken the spring at the mechanical joint area and require strengthening the spring in this region.

\subsection{Design and optimization}

With the extensive use of laminated composite materials in all engineering fields, the optimal design of laminated composites has been an extensive subject of research in recent years. Some of the papers published in this area are given in Refs. [13-16].

Since the composite leaf spring is a mono leaf, it is necessary to optimize the shape of the spring. The designer must make decisions relating to the selection of optimum geometry. This requires a verification of a wide variety of different complicated solutions. Therefore the optimization is carried out with the finite element method using ANSYS software.

3D brick element can be used for modeling the thick, curved and orthotropic structures. 3D shell elements are used for thin structures (the thickness should be onetenth or less than the width and the length). In the middle of composite spring the thickness will increase (about a half of the spring width) to resist the maximum bending moment applied in this area. Compared to the brick elements, using the shell elements need greater number of elements to represent an exact model of spring and consequently the computing time increases. Considering the unidirectional lay up of composite leaf spring, 3D eight-node brick element (SOLID 45) was selected to develop a finite element model of the spring. 


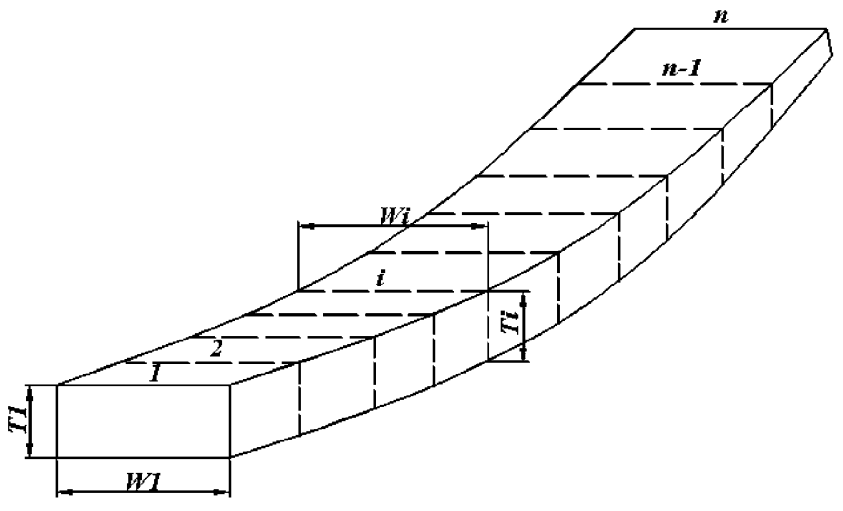

Fig. 3. Choosing DVs for the leaf spring.

\subsubsection{Design variables, constraints and objective function}

Design variables (DV's) are independent quantities that are varied in order to achieve the optimum design. For the leaf spring, the DV's must identify the complete geometry. Spring length and curvature are as the same as the steel spring, so the width and thickness at each cross section along the spring are obvious candidates as the DV's (Fig. 3). On the other hand, the cross-section area must be equal along the spring to ensure that the fiber volume fraction and consequently the mechanical properties of the composites are constant over the length of spring. So to reduce the number of design variables, the cross-section area and the width at each point are selected as DVs. Dividing the constant cross-section area by the width at each point derives the thickness. If $W_{i}$ is the width of $i$ th cross section and $A$ is the crosssection area, the Eq. (3) represents the vector of design variables.

$X=\left[W_{1}, W_{2}, \ldots, W_{i}, \ldots, W_{n}, A\right]$

Constraints are dependent variables and functions of the DV's that constrain the design. Stresses and deflections are limited in the spring and must be considered as constraints. The stress constraint is an inequality constraint to guarantee that the maximum applied stress in the spring is not greater than the material strength. In this work the Tsai-Wu [8] theory was selected as failure criterion to evaluate the stress constraint because it is a simple, versatile, analytical criterion and includes interaction among the stress components (Eq. (4)).

$$
\begin{aligned}
& F_{x x} R^{2} \sigma_{x}^{2}+2 F_{x y} R^{2} \sigma_{x} \sigma_{y}+F_{y y} R^{2} \sigma_{y}^{2}+F_{s s} R^{2} \sigma_{s}^{2}+F_{x} R \sigma_{x} \\
& \quad+F_{y} R \sigma_{y} \leqslant 1
\end{aligned}
$$

where the $\sigma$ 's are stress components, the $F$ 's are strength parameters and $R$ is the safety factor. Failure occurs if the magnitude of the left-hand side of Eq. (4) is greater than one.

The constraint on the deflection is an inequality constraint that ensures the spring under a given load has a specified maximum deflection (Eq. (5)). $\delta=$ Const

Regarding the very closed feasible region of deflection and numerical errors in the finite element methods, using Eq. (5) in the optimization process causes some problems in converging and may not be satisfied. To solve this problem, two constraints $\delta_{1}, \delta_{\mathrm{u}}$ can be defined as illustrated below:

$\delta_{1} \geqslant \delta-\varepsilon$

$\delta_{\mathrm{u}} \leqslant \delta+\varepsilon$

where $\varepsilon$ is a very small value. The effective feasible region is now $2 \varepsilon$, but each constraint has a wide enough range for smooth converging.

Another constraint refers to the variation of width along the spring so that the difference between any two sequent widths (from spring end to the axle seat) must be a positive value (Eq. (8)). This constraint is necessary to prevent converging to an impractical and undesirable local minimum value of the width.

$W_{i+1}-W_{i} \geqslant 0 \quad i=1,2, \ldots, n-1$

Objective function is the dependent variable that must be minimized. One of the most advantageous reasons for considering the composite leaf spring over steel is their very low weight. At the present work the weight of spring is selected as an objective function.

Our optimization problem can be expressed as follows:

\section{Minimize}

$$
W=W\left(W_{1}, W_{2}, \ldots, W_{n}, A\right)
$$

\section{Subject to:}

$$
\begin{aligned}
& F_{x x} R^{2} \sigma_{x}^{2}+2 F_{x y} R^{2} \sigma_{x} \sigma_{y}+F_{y y} R^{2} \sigma_{y}^{2}+F_{s s} R^{2} \sigma_{s}^{2} \\
& \quad+F_{x} R \sigma_{x}+F_{y} R \sigma_{y} \leqslant 1 \\
& \delta_{1} \geqslant \delta-\varepsilon \\
& \delta_{\mathrm{u}} \leqslant \delta+\varepsilon \\
& W_{i+1}-W_{i} \geqslant 0 \quad i=1,2, \ldots, n-1 \\
& \underline{W} \leqslant W_{i} \leqslant \bar{W} \quad i=1,2, \ldots, n
\end{aligned}
$$

\subsubsection{Modeling and optimization}

According to the SAE standard [7] a leaf spring can be considered as two cantilevers. Therefore, in the present work the rear half of spring was optimized first as a cantilever beam and then the front half was optimized based on the results obtained from the rear half. The rear half was divided into 18 segments. Width and thickness at each segment were defined parametrically. Vertical static loading on the spring is $2500 \mathrm{~N}$, so the corresponding reaction on the rear half eye is about 1123 N. Design variables, constraint and objective function were introduced in the software. The ANSYS 5.4 has several techniques for optimization. In this work the first-order method [17] was selected. This method 
uses derivative information, that is, gradients of the dependent variables with respect to the design variables. It is highly accurate and works well for problems having dependent variables that vary widely over a large range of design space.

The optimization process for the rear half converged after about 100 iterations. Fig. 4 shows the variation of objective function (weight) with respect to the iteration number. The minimum obtained weight for the rear half was $888.1 \mathrm{~g}$.

Variation of width and thickness along the spring are shown in Fig. 5. It can be seen that the width increases hyperbolically and the thickness decreases hyperbolically near the axle seat (about $120 \mathrm{~mm}$ along the spring) and then linearly towards the spring eye.

As shown in Fig. 5, at spring end the width and thickness are kept constant. This has been done to avoid the problems that may occur in joining the eyes.

In order to ensure that the optimization process converged to the global optimum point, the spring was optimized using several start points. Table 5 shows the first selected start point and three different start points with their corresponding weight and cross-section area after optimization. It can be seen that the maximum difference between the obtained weights is about $8 \mathrm{~g}$ or $0.09 \%$ and between the cross sections is about $5.67 \mathrm{~mm}^{2}$ or $0.65 \%$. Therefore, there is confidence that the convergence to the global optimum point is achieved.

Having the cross-section area and the width at axle seat and spring end from the optimized rear half, the front half was optimized in the same way. The results

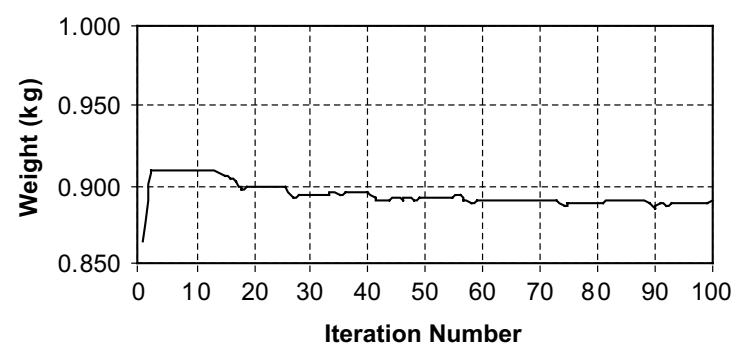

Fig. 4. Variation of spring weight during the optimization loops.

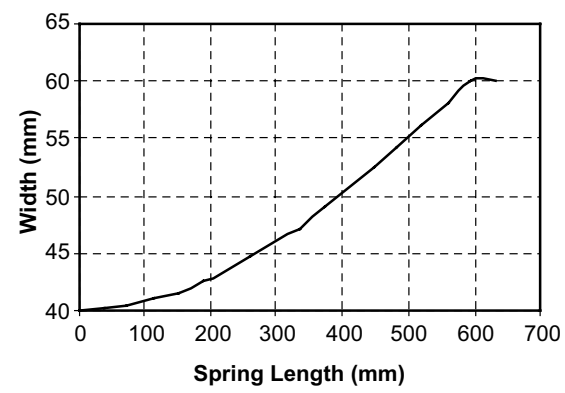

Table 5

Weight and cross-section area obtained from different start points

\begin{tabular}{lllll}
\hline Start point & I & II & III & IV \\
\hline Weight $(\mathrm{g})$ & 888.1 & 890.1 & 895.98 & 890.86 \\
A $\left(\mathrm{mm}^{2}\right)$ & 873.29 & 875.28 & 878.96 & 873.94 \\
\hline
\end{tabular}

showed that the variation of width and thickness is the same as the rear half. The minimum weight of front half was obtained about $719 \mathrm{~g}$. Therefore the weight of full composite spring without considering eye units is nearly $1607 \mathrm{~g}$, which is $80 \%$ lower that the steel spring $(9.2 \mathrm{~kg})$.

\subsubsection{Stress analysis results}

The leaf spring is analyzed under bending loading condition and the normal stresses are important, but because of the anisotropic properties of composites, the other components of the stress tensor must be studied. The longitudinal compression strength of composite used in this work is less than its longitudinal tensile strength, so failure always occurs at the lower (compression) surface of spring. Therefore, in the stress analysis this surface is taken into more consideration. Fig. 6 shows the longitudinal compression stress at the middle of lower surface. Compression stress has its maximum value about $217 \mathrm{MPa}$ near the axle seat and decreases towards the spring eye. At a same loading the maximum stress applied in the steel leaf spring is about

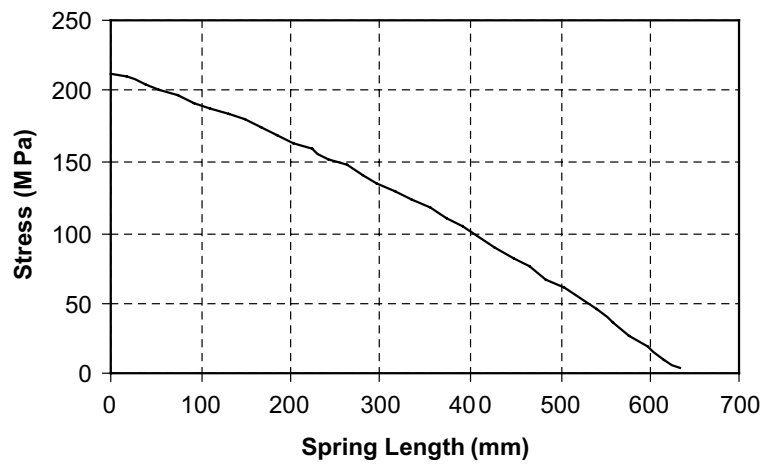

Fig. 6. Longitudinal stress $\sigma_{x}$ at lower surface of composite spring under static vertical loading.

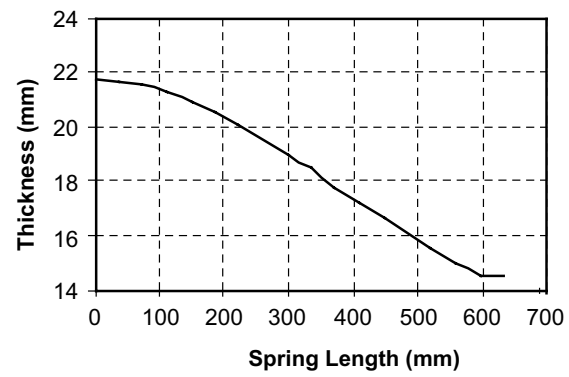

Fig. 5. Variations of width and thickness along the optimized spring. 
$505 \mathrm{MPa}$ from Table 2. The compression strength of fiber glass/epoxy is $450 \mathrm{MPa}$ and the yielding stress of the steel spring is $1175 \mathrm{MPa}$. So the safety factor in steel spring is 2.3 while in the composite spring it is 2.1 . Due to conservative nature of $\mathrm{Tsai}-\mathrm{Wu}$ failure criterion the actual failure load may be greater than the value calculated by this method. The deflection of spring under static loading (Fig. 7) is $120.7 \mathrm{~mm}$, which is very close to the desired value $120.4 \mathrm{~mm}$.

In order to verify the stress analysis, an approximate analytical solution is presented as follows. In this method the curvature of the spring and misalignment of fibers are ignored and the spring is assumed to be a direct cantilever beam as shown in Fig. 8. The deflection $\delta$ at loading point $P$ is:

$$
\begin{aligned}
\delta & =\frac{\partial u}{\partial p}=\frac{\partial}{\partial p} \int_{0}^{l} \frac{M_{(x)}^{2}}{2 E_{(x)} I_{(x)}} \mathrm{d} x=\frac{\partial}{\partial p} \int_{0}^{l} \frac{p^{2}(l-x)^{2}}{2 E_{x x} I_{(x)}} \mathrm{d} x \\
& =\frac{\partial}{\partial p}\left[\frac{p^{2}}{2 E_{x x}} \int_{0}^{l} \frac{(l-x)^{2}}{\frac{W_{(x)} t_{(x)}^{3}}{12}} \mathrm{~d} x\right] \\
& =\frac{12 p}{E_{x x}} \int_{0}^{l} \frac{(l-x)^{2}}{W_{(x)} \frac{A^{3}}{t_{(x)}^{3}}} \mathrm{~d} x=\frac{12 p}{E_{x x} A^{3}} \int_{0}^{l}(l-x)^{2} W_{(x)}^{2} \mathrm{~d} x
\end{aligned}
$$

where $U$ is the stored strain energy in the beam, $l$ the length of beam, $W_{(x)}$ and $t_{(x)}$ the width and thickness of cross section, $P$ the applied load, $E_{(x)}$ the modulus of elasticity in the longitudinal direction which in this case is equal to the modulus of elasticity along the fibers $E_{x x}$, $M(x)$ the bending moment at a cross section, $A$ the cross-

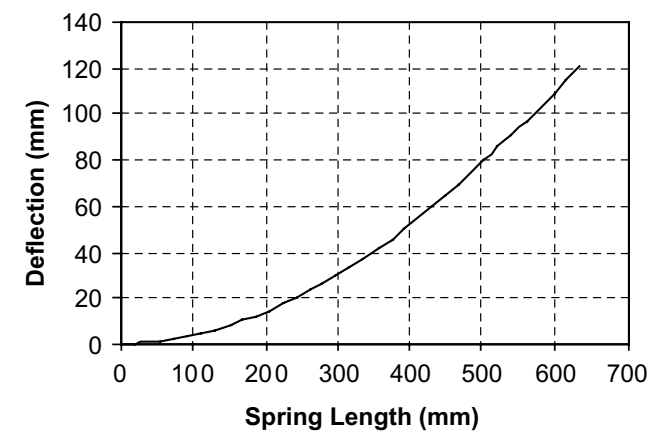

Fig. 7. Deflection of composite spring under static vertical loading.

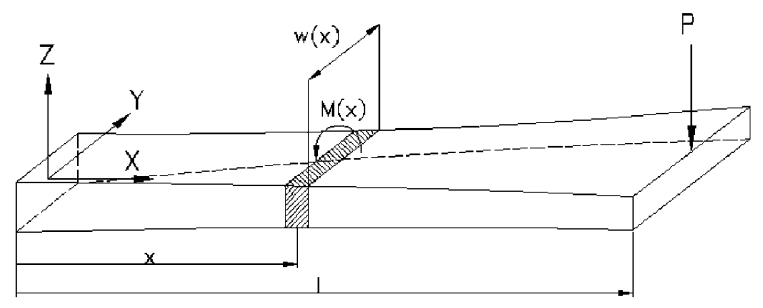

Fig. 8. Approximated model of rear half of spring for analytical solution. section area and $I_{(x)}$ is the second moment of area. It is assumed that the spring width $W_{(x)}$ is hyperbolically and is obtained from Fig. 5. Substituting the related value, the deflection of the spring is

$\delta=147.6 \mathrm{~mm}$

The maximum induced normal stress at axle seat is

$\sigma=\frac{p l t / 2}{w t^{3} / 12}=\frac{6 p l}{w t^{2}}=242.3 \mathrm{MPa}$

where $w$ and $t$ are the width and thickness of spring at axle seat.

Regarding the rough approximations used in this solution, it can be seen that the results of stress analysis with the finite element method $(\delta=120.7 \mathrm{~mm}$ and $\sigma=$ $217 \mathrm{MPa}$ ) are acceptable.

\subsubsection{Case studies}

3.3.4.1. Maximum loading analysis. Maximum loading on a leaf spring is shown in Fig. 1. Because the forces applied in the accelerating and braking situations are more critical in the front half of spring, therefore the front half is analyzed under maximum loading. The vertical force in the full bump is about $4660 \mathrm{~N}$, so the front half should carry $2568 \mathrm{~N}$. The longitudinal forces are produced by the change in the linear momentum of vehicle during the brake or accelerating processes. Assuming that the velocity of car from $120 \mathrm{~km} / \mathrm{h}$ reaches to $0 \mathrm{~km} / \mathrm{h}$ in $5 \mathrm{~s}$, the maximum longitudinal force will be $3000 \mathrm{~N}$. The side loads are produced by the change in the angular momentum of vehicle in the bends of road. This force is usually assumed to be $75 \%$ of the vertical loads [5]. Therefore in this work it is $1927.5 \mathrm{~N}$. The wind up torque is produced when one of the rear wheels moved up and the other moved down, so the axle will twist. The twist angle of $9^{\circ}$ is the maximum possible twist angle between the axle seat and each eye [5]. Fig. 9 shows the full loading on the front half of spring with the magnitude of every load. Figs. 10-12 show the results of front half stress analysis. As shown in Fig. 10, the maximum normal stress in the longitudinal direction $\sigma_{x x}$ is about $314 \mathrm{MPa}$. This stress is induced at axle seat near the inside edge of the spring, because at this point the stresses due to the vertical and side loads are com-

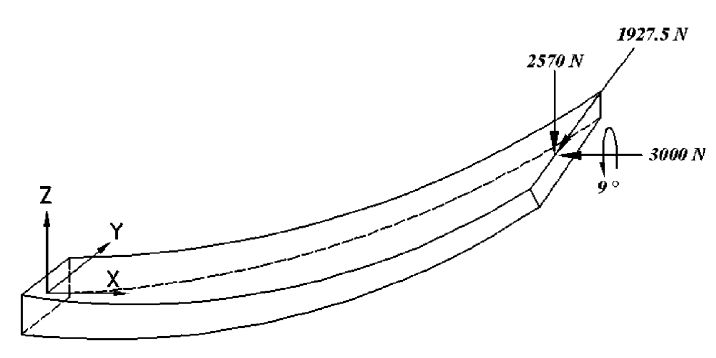

Fig. 9. Full loading applied to the front half of spring. 


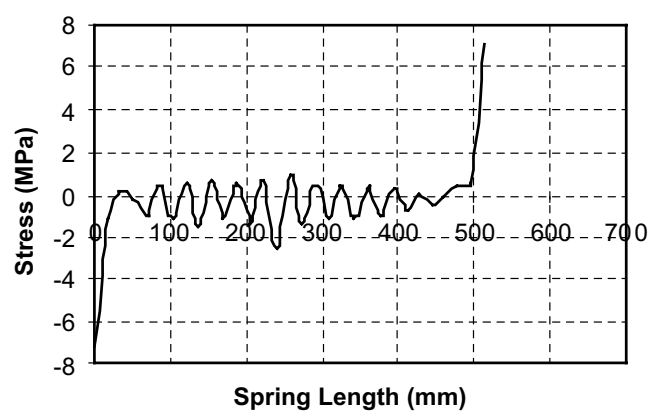

Fig. 10. Longitudinal stress $\sigma_{x}$ at lower surface of composite spring under full loading.

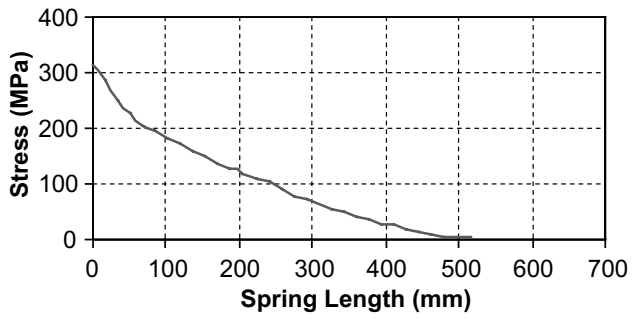

Fig. 11. Transverse stress $\sigma_{y}$ at lower surface of composite spring under full loading.

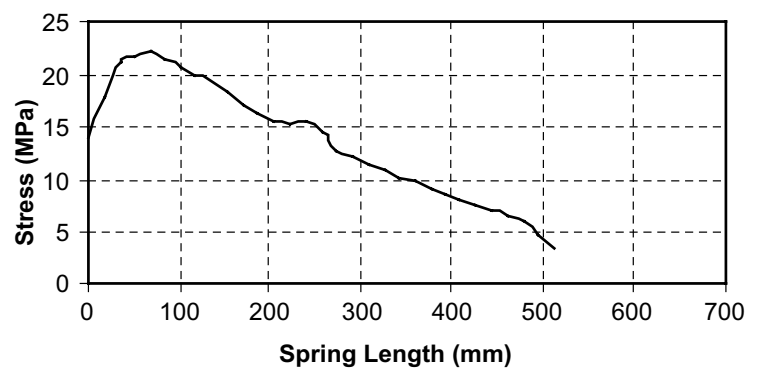

Fig. 12. Longitudinal stress $\sigma_{x y}$ at lower surface of composite spring under full loading.

bined. At a same loading the maximum normal stress in the steel spring is about $928 \mathrm{MPa}$. So the safety factor of the steel spring is 1.3 while in the composite spring that is 1.4. The transverse stress (normal to the direction of fibers) $\sigma_{y y}$ is shown in the Fig. 11 . The stress $\sigma_{y y}$ varies a little along the spring and its maximum value is about 32.6 MPa. The shear stress $\sigma_{x y}$ is shown in Fig. 12. Also in this case because of the combination of the loads, the stress $\sigma_{x y}$ has its maximum value about $43 \mathrm{MPa}$ in the middle of the spring at the axle seat.

3.3.4.2. Natural frequency. The road irregularities usually have the maximum frequency of $12 \mathrm{~Hz}$ [5], so the leaf spring should have a higher natural frequency to avoid the resonance. The stiffness of composite leaf
Table 6

The first five natural frequencies of composite leaf spring

\begin{tabular}{llllll}
\hline$f(\mathrm{HZ})$ & 1 & 2 & 3 & 5 & 6 \\
\hline $\begin{array}{c}\text { Steel leaf } \\
\text { spring }\end{array}$ & 29.6 & 51.8 & 94.9 & 102.5 & 134.3 \\
$\begin{array}{c}\text { Composite } \\
\text { leaf spring }\end{array}$ & 33.3 & 57.6 & 173.1 & 248.9 & 464.2 \\
\hline
\end{tabular}

Table 7

Results of stress and deflection analysis of leaf spring from the two methods: linearly elastic behavior, large deformations behavior

\begin{tabular}{lll}
\hline Material behavior & $\begin{array}{l}\text { Max. longitudinal } \\
\text { stress }(\mathrm{MPa})\end{array}$ & $\begin{array}{l}\text { Max. deflection } \\
(\mathrm{mm})\end{array}$ \\
\hline Linearly elastic & 217 & 120.7 \\
$\begin{array}{c}\text { Large deformations } \\
\text { and small strains }\end{array}$ & 224 & 131 \\
\hline
\end{tabular}

spring is the same as the steel leaf spring but its weight is lower than the steel spring. Therefore, we can expect that the first natural frequency of composite leaf spring will be higher than that of the steel one. Using ANSYS the first five natural frequencies of steel and composite leaf springs are listed in Table 6.

Considering the Table 6 , it is obvious that first natural frequency of leaf spring is nearly three times the road frequency and resonance will not occur.

3.3.4.3. Large deformations. Due to the large deflection of spring it may be seem that the leaf spring is not under small deflection conditions and has large deformation and small strains behavior. Applying this behavior in the spring design causes a high degree of nonlinearly to the problem, so the optimization process will be computationally intense and may not converge. To ensure that the results of linearly elastic assumption are reliable, the optimized leaf spring is analyzed assuming the large deformations and small strains behavior. Table 7 shows the results of the two methods. With respect to the small difference between the results of the two methods it is more reasonable to use the linearly elastic assumption and avoid large deformation theory.

\section{Joints design}

Heretofore, the composite leaf spring was designed and optimized. In order to provide a reliable suspension system, the leaf spring should have appropriate joints to be fixed to the axle and the vehicle body. Four types of joints are shown in Fig. 13 that can be used to attach the spring to the vehicle body.

Considering Fig. 13, the joint type (a) consists of a steel eye that can be bolted or pinned to the spring. Because of drilling, a region of stress concentration 


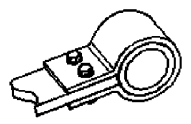

(a)

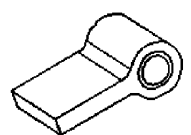

(b)

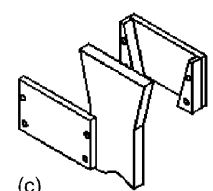

(c)

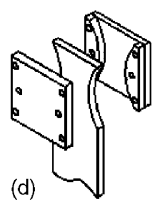

Fig. 13. Different joints to attach the composite leaf spring to the vehicle body.

will exist around the holes in this type of attachment. Simplicity and low cost are the advantageous of this attachment. In joint type (b) the eye and spring are manufactured simultaneously from the same material. In this type there is no stress concentration. But reinforcement of composite at the junction of eye and spring is necessary to avoid the splitting of unidirectional fibers. Difficulties of manufacturing and high cost are disadvantages of this method. In joint types (c) and (d) the spring end has a conical or concave width profile so that the steel eye fittings with the same conical or concave profile can be mounted easily and reliably, together with rubber pads. In these joints there is no stress concentration due to the drilling, but the cost of manufacturing of the conical or concave parts of spring should be considered. On the other hand the angle of conical parts should be selected great enough to avoid squashing the composites that may cause some problems due to available space. Joint type (d) is used by $\mathrm{Yu}$ and Kim [5].

The joint type (a) is the simplest and cheapest one from the manufacturing point of view. Although in this case the composites should be drilled, in the present work this joint was analyzed if it satisfies the strength requirements, it should be used. Due to the critical loading on the front half, the eye in this area is considered.

The leaf spring under loading is nearly flat, so the longitudinal and side loads are the forces that act at the spring eyes. The spring end at front half with the maximum loading condition is shown in Fig. 14. For simplicity, it is assumed that the dimensions of spring are 60 $\mathrm{mm}$ wide, $60 \mathrm{~mm}$ long and $12.8 \mathrm{~mm}$ thick. Two holes

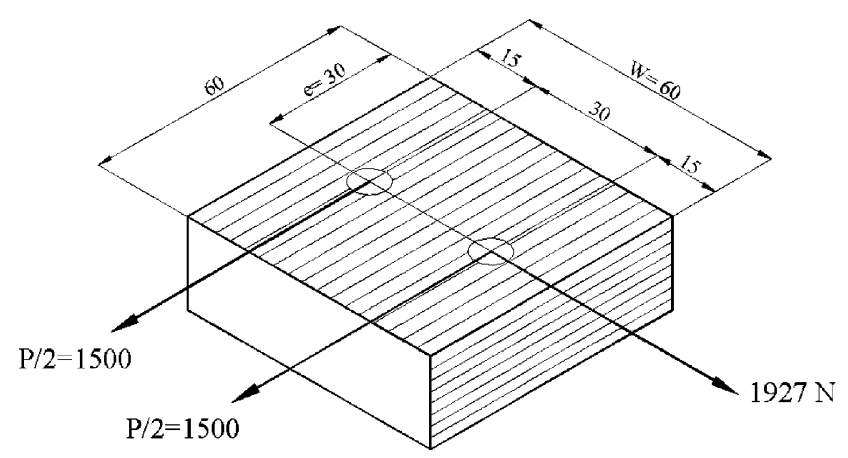

Fig. 14. The spring end at front half with maximum loading. with the diameter of $8 \mathrm{~mm}$ are considered in order to attach the steel eye.

Among the main failure modes in mechanical joints in composites [18-20], tension and shear out failures may occur. But it should be considered that the fibers are unidirectional along the spring. In this case the amount of actual failure stresses are considerably lower that the calculated stresses. In fact, in these cases the failure does not occur due to tension or shear out but rather the failure occur because of splitting the composite in the direction of fibers. To avoid this failure and reinforcement of composite, additional layers with different directions were laid around the holes. At the present work the lay up of $\left[ \pm 45^{\circ} / 0^{\circ} / 90^{\circ} / \pm 45^{\circ} / 0^{\circ} / 90^{\circ} /\right.$ $\left.\pm 45^{\circ}\right]$ is used at the upper and lower surface of spring ends around the holes to strengthen the composite material in these areas.

The spring is analyzed with the additional lay up at spring end. The results showed that the maximum stresses $\left(\sigma_{x x}=6.82 \mathrm{MPa}, \sigma_{y y}=11.7 \mathrm{MPa}, \sigma_{x y}=13.7\right.$ $\mathrm{MPa}$ ) are acting around the holes at an angle of $45^{\circ}$ to the direction of fibers. By substituting these stresses in the Tsai-Wu failure criterion (Eq. (4)), the left-hand side of the inequality becomes 0.2 . Therefore, the critical loading on the eye is supportable with the composite. Consequently, the joint of type (a) was selected to join the spring to the vehicle.

\section{Summary and results}

A steel leaf spring used in the rear suspension of light passenger cars was analyzed by two analytical and finite element methods. The experimental results verified the analytical and the finite element solutions.

The steel leaf spring was replaced with an optimized composite one. Main consideration was given to the optimization of the leaf spring geometry. The objective was to obtain a spring with minimum weight that is capable of carrying given static external forces by constraints limiting stresses (Tsai-Wu criterion) and displacements.

The results showed that the optimum spring width decreases hyperbolically and the thickness increases linearly from spring eye towards the axle seat.

The stresses in the composite leaf spring are much lower than that of the steel spring.

Compared to the steel leaf spring $(9.2 \mathrm{~kg})$ the optimized composite leaf spring without eye units weights nearly $80 \%$ less than the steel spring.

The natural frequency of composite leaf spring is higher than that of the steel leaf spring and is far enough from the road frequency to avoid the resonance.

To join the spring to the vehicle body, an additional lay up was used on the spring end and the steel eyes were mounted through bolts. 


\section{References}

[1] Beardmore P, Johnson CF. The potential for composites in structural automotive applications. Comp Sci Technol 1986;26: 251-81.

[2] Beardmore P. Composite structures for automobiles. Comp Struct 1986;5:163-76.

[3] Morris CJ. Composite integrated rear suspension. Comp Struct 1986;5:233-42.

[4] Daugherty RL. Composite leaf springs in heavy truck applications. In: Composite Materials, Proceedings of Japan-US Conference, Tokyo, 1981, p. 529-38.

[5] Yu WJ, Kim HC. Double tapered FRP beam for automotive-suspension leaf spring. Comp Struct 1988;9:279300.

[6] Corvi A. A preliminary approach to composite beam design using fem analysis. Comp Struct 1990;16:259-75.

[7] Manual on design and application of leaf springs, Spring Design Manual, AE-11, Society of Automotive Engineer Hs $788,1990$.

[8] Tsai SW, Hahn HT. Introduction to composite materials. Technomic Publishing; 1980.

[9] ANSYS 5.4, ANSYS Inc., 1997.

[10] Ryan WE. Method of making a molded fiber reinforced plastic leaf spring, US patent 4,560,525 (24/12/1985).
[11] Richard DS, Mutzner JE, Eilerman JF, et al. Method of forming a composite leaf spring with fabric wear pad, US patent 4,894 , $108(16 / 1 / 1990)$.

[12] Nickel HW. Bushing construction for a fiber reinforced plastic leaf spring, US patent 4,565,356 (21/1/1986).

[13] Abrate S. Optimal design of laminated plates and shells. Comp Struct 1994;29:269-86.

[14] Kam TY, Snyman JA. Optimal design of laminated composite plates using a global optimization technique. Comp Struct 1991;19: $350-71$.

[15] Conecicao CA, Torres Marques A, Soeiro AV. Optimization of laminated composite structures using a bilevel strategy. Comp Struct 1995;33:193-200.

[16] Liu IW, Lin CC. Optimum design of composite wing structures by a refined optimality criterion. Comp Struct 1991;17:51-65.

[17] Nanderpleats GN. Numerical optimization techniques for engineering design: with applications. New York: McGraw-Hill Publishers; 1984.

[18] Mallick DK, editor. Composite engineering handbook. Marcel Dekker; 1997. p. 720-36.

[19] Dreger DR. Design guideline for joining advanced composites, Machine Design, 8 May 1980, pp. 89-93.

[20] Hart-Smith LJ. Mechanically fastened joints for advanced composites, phenomenological consideration and simple analysis, Fibrous Composites in Structural Design, Premium Press, 1993. 